\title{
Leadership Standards: Marginalizing Diversity
}

\author{
Joe Corrigan* \\ * Educational Policy Studies, University of Alberta \\ 7-110 Education North, Edmonton, Alberta T6G 2G5, Canada \\ E-mail: joe.corrigan@ualberta.ca
}

Received: April 1, 2012 Accepted: May 1, 2012 Published: May 17, 2012

doi:10.5296/ije.v4i2.1578 URL: http://dx.doi.org/10.5296/ije.v4i2.1578

\begin{abstract}
This article adopts a macro perspective on the role of leadership standards to comment on the sociological impact of their implementation. Where the growing diversity of learners in Canadian schools has invited a pluralism of ideas, research methods and approaches to learning, leadership standards induce increasingly homogenized responses to complex learning environments. Using a Constructionist theory of knowledge and Foucault's conceptualization of power, this article asserts leadership standards subordinate the agency of educational leaders. This article will be of interest to educators and educational leaders who must balance administrative priorities with increasingly diverse learner needs.
\end{abstract}

Keywords: leadership; diversity; leadership standards; organizational theory 


\section{Introduction}

"A stupid despot may constrain his slaves with iron chains; but a true politician binds them even more strongly by the chain of their own ideas" (Foucault, 1979, p. 102). This is a paper that works to establish how diverse individual understandings that contribute to pluralism in research are overwritten by the normative influences of leadership standards. The scholarship and theory in Educational Administration (EA) ought to be what advances the practice of education administration in schools, because at its best it is a collection of competing lenses that have a pervasive impact on how educators see and frame problems. Schools are complex, and when competing methods of enquiry are harnessed to support contribution to practice, they help develop another generation of leader-citizenry. However, the conduct of education is also subject to ideological influence, and I believe leadership standards represent a particularly insidious form of interference. This observation is a statement not only of my own perspective and paradigmatic commitments, but also the methodological biases my particular forms of enquiry construct and insist upon. When ideology subverts experimentation and responsible risk-taking, and where reasonable people mimic the actions of others instead of openly debating ideas on merit, I suggest that leadership standards will have achieved their purpose.

\section{Metaphor Shapes Perception and Practice}

A metaphor or theory of schools has a profound impact on what we look for and how we see them. Sergiovanni (1994) challenged us to think of schools as communities rather than simply organizations. If we think of schools as organizations, it is understandable because as the author reminds us, that is where "educational administration borrows its fundamental frames for thinking about how schools should be structured and coordinated, how compliance within them should be achieved, what leadership is, and how it works" (p. 215). An industrial framework will provide one understanding of motivation, conflict and collaboration, and community another. The author cautions that applying a frame of 'community' onto something that is understood underneath as an organization is different than originally framing it as a community. English (2008) asserts these 'linguistic conceptual systems' are critical to our individual understandings based within culture. He cited work by Lakoff and Johnson (1980), and the Sapir-Whorf hypothesis, as ways to understand how culture and language construct reality, impact cognition and reinforce previously established worldviews.

The impact of metaphor is not limited to our conception of schools, but instead actively shapes our worldview in all that we do. "Such metaphors profoundly, and often unconsciously determine our attitudes to the world, to people, to events and to actions (Bates, 1982, p. 13). English (2008) describes how language, causality and context are self-reinforcing, and the "external world is 'trimmed' to 'fit' the 'worldview' of the perceiver" (p. 54). Although a cliché to frame human cognition in a computer metaphor, our cognitive patterns might be thought of as an operating system running certain software. Not all files (new experience or data which challenges our psycho-social identity) are compatible with the operating system, and those that are not compatible with these operational parameters are excluded from active consideration. This provides a consistency to cognitive processes that work to reinforce our 
way of looking at the World. We project frames from resource domains (previous experience) on to target domains (new situations) as an anticipatory strategy to establish meaning (Lakoff \& Johnson, 1980). The temporal, emotional, and social elements of identity and the human condition add layers of complexity to these cognitive processes. We are not the purveyors of a human cognition as 'computer' metaphor that 'calculates' an answer or response to social context. Instead, individuals work to make coherent their own socially constructed cognitive landscape - a view that originates in previous experience.

The application of metaphor and the framing of events and ideas are critical to both paradigms of enquiry and relations of power within society. The use of metaphors and the analysis of their use invites our attention because "such metaphors not infrequently obscure the interests of dominating elites and present particular partisan views of the world as incontestable descriptions of the way things are" (Bates, 1982, p. 13). This claim of inevitability or neutrality is a substantial problem for a Constructionist theory of knowledge, because it suggests knowledge resides 'somewhere out there' and diminishes the notion that what constitutes 'knowledge' depends upon individual perception. If it occurs to the perceiver to question a frame or metaphor, their sense of security and self-efficacy will also play a role in determining whether they do or not. Apple $(1993,2006)$ suggests 'common sense' notions of efficiency and effectiveness may be presented as neutral in a depoliticized discursive strategy, but in reality they serve specific ideological interests in a variety of important ways.

Metaphor may also be expressed in cultural ritual and routine, and this makes them more powerful because "they are unconsciously followed and unquestionably accepted" (Bates, 1982, p. 17). Of course not all are unquestionably accepted, but they may have their greatest influence over us when we do not see them, or when we do not realize that we are operating within them. For example, when a sales representative from the company selling a previously owned vehicle suggests 'they would rather make a friend, than a profit,' we might become sceptical of the proffered frame. However, when an educator in a public junior high school presents early Canadian history from the point of view of European settlers, it may be more difficult to ascertain our own position within power relations and the colonizer frame of reference, yet we all clearly participate in society from a specific political and ideological perspective. Freire (2000) argues that whether maintaining existing power structures or promoting change, education is not neutral. By acknowledging the role of metaphor in understanding, the idiosyncratic nature of human cognition and the selective nature of our perception, I argue that paradigms of research and methods of enquiry are tenuous extensions built upon the wobbly foundation that characterizes human cognition.

\section{Research Pluralism in Educational Administration}

Given the necessarily elusive status of 'fact' when mediated through metaphor, perception and cognition, it is easy to imagine competition among systems claiming 'truth' through various systems of thought and means of enquiry. These systems of thought acquire and manage knowledge through various paradigms of enquiry. English (2008) defines 'paradigm' as a "norm of behavior that applies to scientific investigations in which investigators/researchers share certain assumptions about what is or is not worth researching 
and how best to go about the process of inquiry" (p. 27). Consider two opposing endpoints on a continuum that include all other paradigms of enquiry between them, with positivists, objectivists and empiricists on one side and subjectivists and constructivists representing the other. For EA to be of value to practitioners it is critical that we use all tools across the continuum and avoid dogmatic positions. Given our individual predispositions to reject, misrecognize or discount information that does not fit into our own individual cognition patterns and worldview, it is doubly important that multiple paradigms and methods of enquiry are used. The academic exchange and debate needed to dynamically advance horizons of knowledge in an increasingly pluralistic society insists upon a multidisciplinary format where responsible risk-taking and experimentation will flourish.

Knowledge is situated within social and political contexts. The same cognitive predispositions or schemas that work to build paradigm loyalty and commitment throughout graduate school, work to exclude information that would support alternative understandings and theoretical models. This contributes to a 'politics of methodology' among practitioners and researchers that link directly to the aspirations of EA as an institutionally located field of enquiry that competes for status and acceptance against other fields. Cannon and Griffith (2007) use the term 'confirmation bias' to describe a phenomenon where people seek data "that confirms what they want to believe or think they already know" (p. 137). Groups are established around the pursuit of knowledge through paradigms and institutional silos, and the hosting of knowledge within social and sociological processes has a political dimension.

Barlosky (2006) has described Greenfield as an important figure in EA and a capable proponent of seemingly incommensurate (empiricist or rationalist) modes of enquiry, albeit at different times in his career. Was Greenfield correct? When? From the perspective of the Theory Movement and the Vienna Circle, where observation, mathematics, scientific method and enquiry methods favored by the natural sciences were influential, Greenfield was correct in the early part of his career (English, 2008). It seems clear the quantitative methodologies employed by Greenfield in his graduate work at the University of Alberta would inform EA policy and practice through the rigorous application of statistical methodology. These quantitative methods may have been put to exceptionally good use in studying certain measurable or quantifiable elements of the educational system. His approach may have brought larger patterns into focus, where previously this activity or behavior pattern may have gone unnoticed or been dismissed as an exception. These methods are filled with possibility, and cohering data from a variety of jurisdictions could make a panoptic level of school observation and comparison possible. However, these same methods also obscure the history and social context of learners, individual schools, and the social contexts in which they reside. Whether inadvertently or by design, these methods project and perpetuate a metaphor onto schools as meritocracies that offer an 'even playing field' to a diverse group of learners.

Quantitative methods are highly effective in studying certain types of problems, but they can become awkward, indirect and ineffective ways of understanding the individual and individual agency. This is because socially defined educational phenomena such as leadership are embedded within value-laden culture, and "values cannot be established with scientific (empirical) procedures" (English, 2008, p. 96). A second problem is that if we understand 
schools through the metaphor of an 'even playing field' then it is individual agency that will determine success or failure. If you consciously or unconsciously accept the metaphor of an 'even playing field' in schools, you may also be inclined to accept a consistent and reinforcing worldview for society. The 'even playing field' metaphor regards the poor of society as the authors of their own misfortune, and the rich as having earned a privileged economic status through hard work and fair competition. A populist and persistent portrayal of schools within this egalitarian metaphor promotes acceptance, along with clusters of associated views about political and economic agency. The metaphor strips away the historical, social and political context, and makes the universal abstraction of the learner an accepted practice. From this perspective, the socio-economic status of where a school may be situated is not an appropriate focus for EA because the individual child is the unit of analysis, and when abstracted ultimately responsible for their own success or failure. Finally, in this metaphor, schools that do not produce strong test scores will be fixed through competition, and a "claim that the invisible hand of the market will inexorably lead to better schools" (Apple, 2006, p. 471).

In this section, I have described how paradigms organize our thoughts and promote modes of enquiry that illustrate and obscure different forms of knowledge. The paradigms and related metaphors we use to mediate our relationship with reality are important because they influence how we see the World. In EA, we depend upon a multiplicity of views to promote knowledge pluralism, debate and the prevention of insularity. One person might use an 'even playing field' metaphor, while another might see structural sources of inequality in Correspondence Theory, where the "the social relationships of economic life...[are]...replicated in the educational system and in family life" (Bowles \& Gintis, 1976, p. 147). I have not tried to argue the merits of these perspectives here, but only wish to establish that through a variety of mediating frames, metaphors and paradigms, we create our own unique worldviews that compete, and have implications for EA research and practice. These mediating structures are self-interested and reflexive, as they work to establish coherent meaning and govern our participation in the World around us. This discussion serves as a foundation for exploring how the social construction and implementation of 'standards' may serve the political and sociological interest of schools as a medium of social control, but I argue, only at great expense to EA as a field of enquiry.

\section{Leadership Standards: A Regime of Truth}

Using my own variation of an argument advanced by English (2003, 2006, 2008), I argue against the notion of leadership standards in general, but do not review individually the Interstate School Leaders Licensure Consortium (ISLLC) Standards or the Principal Quality Practice Guideline (PQPG) that may soon become a requirement in Alberta. Common concerns related to leadership standards might include the static and arbitrary nature of the relevant body of knowledge, the reductionist approach taken in defining it, and the discounting of judgment and experience in assessment for accreditation. As important as these and other issues may be, I believe the central and fundamental problem with leadership standards is the way they operate to narrow the band of leadership behavior in service to increasingly complex and diverse educational settings.

My central argument is that standards reduce the professional status, discretion and 
creativity of educational leaders through the exercise of a homogenizing and hegemonic power. English (2006) asserts the ISLLC standard has "not only proven detrimental to the profession generally, and the professoriate specifically, but that it has actually lowered the standards for leadership preparation" (p. 462). Why? People may disagree over what metaphor to use when thinking about schools, but there ought to be little disagreement they are increasingly complex and demanding work and learning environments (Levin, 2008). Schools in Canada have an increasingly diverse and technology-savvy student base that form a constituency within schools that are subject to ongoing comparison, ranking and competition for funding and student enrollment. I argue the complexity resident in these communities is not well served by a static body of knowledge proposing 'one size fits all leadership.' I suggest this notion is fundamentally at odds with the dynamism of contemporary schools that operate day-after-day among the competing expectations of parents, learners, educators, politicians and society. Perhaps most importantly, the hegemonic influence within EA that is created by the standards is itself a projection of social reality that advances certain interests, even while it oppresses "those of other people at the same time" (Greenfield, 1980, p. 33).

English (2008) used Foucault's 'regime of truth', 'power knowledge' and political 'apparatus' to describe the role of standards in producing hegemonic influence. First, he suggests that a "monolithic, uncontested, internally consistent fount of universally accepted stipulations and axioms and tenets for an academic discipline is an illusion, supported only in the case of accreditation by a forged, muscular application of a raw political power" (English, 2006, p. 462). The heterogeneity and complexity of schools and the myriad of paradigmatic approaches that support and maintain democratic values and diversity in EA scholarship are lost within the production of standards as an exercise of power. In addition, it is the clarity and apparent neutrality of the standards that work to stifle opposition, marginalize difference and reduce opposition through hegemonic influence. By articulating and maintaining a highly specific standard, central authorities retain the interpretive function or 'normalizing gaze' over what constitutes compliant or non-compliant behavior. This is a particularly important and effective device in homogenizing behavioral norms. I suggest this form of power reduces the importance of what is in the standards, because 'real' power is exercised by a panoptic central authority that determines what constitutes compliant or non-compliant behavior.

Hegemonic power and influence is silent and invisible. It is a highly efficient exercise of power because "if the prisoner is never sure when he is being observed, he becomes his own guardian" (Foucault, 1979, p. 19). The 'power knowledge' incarnated within leader standards is generated and regenerated horizontally through discourse, and as peers observe and interact with each other to guide their own conduct in relation to the standards. Once the subject internalizes the standard, observation requirements are reduced and there will be little resistance to disciplinary measures. Foucault would be interested in the social, historical, and political origins of the standards, because this archeology would illuminate 'real' relations of power within the society where the standards have surfaced. For standards to be deployed in a depoliticized and neutral discursive strategy as described by Apple (2006), the subject of the standards must voluntarily assume them. This internalization is exacerbated by the 
knowledge that a centralized power is evaluating compliance, and "for sanctions to work....the actions have to be perceived as unambiguous, non-political and fairly applied" (English, 2003, p. 32). Hegemonic power and influence are embedded in the attitudes, beliefs and culture of society and it is a conceptual, political and social technology that is not easily reached through positivist, empirical, or behavioral enquiry methods.

Standards such as ISLLC represent a 'regime of truth' that is fundamentally an exercise of power with its origin in social, historical and political processes. The application of standards is not an effort to develop educational leadership talent and ability, but a way to harness and constrain educational leaders through additional and redundant accountability measures. In this context, it would not be unusual for research support to be valued according to the degree to which it supported, refined or otherwise maintained the leadership standards. By securing a 'normalizing gaze' that is sure to homogenize behavior and inhibit risk-taking among educational leaders, the agenda of today's political hierarchy is advanced as the frames, metaphors and paradigms which project and sustain their particular social reality maintain dominance. Foucault (1979) has said "each society has its regime of truth, its 'general politics' of truth: that is, the types of discourse which it accepts and makes function as true" (p. 73). English (2006) has also said once a knowledge base is established by political means, it is difficult to change and 'true' by definition. What does this mean for educational leadership in relation to democratic values and diversity?

\section{Implications for Education Administration}

My focus has been on the Orwellian operation of leadership standards and the stultifying effect I believe they will have on leaders in schools. This discussion has described how standards subordinate individual agency, personal experience, and research pluralism to the homogenizing influence and normalizing structures inherent in leadership standards. A diversity of worldviews and ideas creates the opportunity for the co-creation of knowledge and practice between leaders and led. With leadership standards, we have great emphasis and focus on the leader, which signals a hierarchical conception of schools as organizations. It is also consistent with another wave of Theory Movement influence as a central authority works to measure learning by universally abstracting students and standardizing school policy, so that comparison and evaluation are able to proceed regardless of social context. By homogenizing educational leadership practice through the implementation of standards, both research and practice will be subordinated to supporting the projection of the 'even playing field' metaphor. Central authority can be confident that educational leaders will be more concerned about raising their comparative benchmarks, than asking whether or not those benchmarks make any sense within their school community. 


\section{References}

Apple, M. W. (1993). Official knowledge: Democratic education in a conservative age. New York, NY: Routledge.

Apple, M. W. (2006). Producing inequalities: Neo-liberalism, neo-conservatism and the politics of educational reform. In H. Lauder, P. Brown, J. Dillabough, \& A. H. Halsey (Eds.), Education, globalization \& social change (pp. 468-489). Oxford \& New York, NY: Oxford University Press.

Barlosky, M. (2006). Greenfield, Thomas Barr. In English, F. W. (Ed.) Encyclopedia of educational leadership and administration. Thousand Oaks, CA: Sage.

Bates, R. J. (1982, March). Towards a critical practice of educational administration. Paper session presented at Annual Meeting of the American Educational Research Association, New York, NY.

Bowles, S., \& Gintis, H. (1976). Schooling in capitalist America: Educational reform and the contradictions of economic life. New York, NY: Basic Books.

English, F. W. (2003). Cookie-cutter leaders for cookie-cutter schools: The teleology of standardization and the de-legitimization of the university in educational leadership preparation. Leadership and Policy in Schools, 2(1), 27-46.

English, F. W. (2006). The unintended consequences of a standardized knowledge base in advancing educational leadership preparation, Educational Administration Quarterly, 42(3), 461-472. http://dx.doi.org/10.1076/lpos.2.1.27.15254

English, F. W. (2008). The art of educational leadership: Balancing performance and accountability. Thousand Oaks, CA: http://dx.doi.org/10.1177/0013161X06289675

Foucault, M. (1979). Discipline and punish: The birth of the prison. New York, NY: Vintage Books.

Freire, P. (2000). Cultural action for freedom. Center for the Study of Development and Social Change. Cambridge, MA: Harvard Educational Review.

Lakoff, G., \& Johnson, M. (1980). Metaphors we live by. Chicago, IL: University of Chicago Press.

Levin, B. (2008). How to change 5000 schools: A practical and positive approach for leading change at every level. Cambridge, MA: Harvard Education Press.

Sergiovanni, T. (1994). Organizations or communities? Changing the metaphor changes the theory. Educational Administration Quarterly, 30(2) 214-226, Thousand Oaks, CA: Sage. http://dx.doi.org/10.1177/0013161X94030002007 


\section{Copyright Disclaimer}

Copyright reserved by the author(s).

This article is an open-access article distributed under the terms and conditions of the Creative Commons Attribution license (http://creativecommons.org/licenses/by/3.0/). 